\title{
REVIEWS
}

\section{Chest pain evaluation units}

\author{
Gareth Quin
}

Chest pain is a common cause of accident and emergency (A\&E) presentation. In the United States, it accounts for 5-6\% of new emergency department attendances. ${ }^{12}$ The principal challenge in these patients is to identify those with an acute coronary syndrome (ACS). Early diagnosis allows effective treatment and inadvertent discharge may have disastrous consequences for patient and doctor: in the United States, between $2-5 \%$ of acute myocardial infarctions (AMI) are discharged from the emergency department and $20 \%$ of malpractice claims against emergency physicians relate to the management of ACS. ${ }^{3}$

The problem with the A\&E assessment of these patients lies in the limitations of diagnostic tests for acute coronary ischaemia-initial ECG is diagnostic of AMI in only $40-65 \%$ of patients and is even less useful in unstable angina. ${ }^{4}$ Despite recent advances, serum markers for myocardial necrosis detect, at best, $66 \%$ of AMIs on arrival. ${ }^{5}$ Faced with these diagnostic difficulties and the consequences of misdiagnosis, A\&E physicians have a low threshold for admitting patients with chest pain in whom the diagnosis is not immediately clear. Some $60-65 \%$ of these patients have an eventual diagnosis of non-cardiac chest pain ${ }^{3}$ and while serious pathology is diagnosed in a minority, this traditional approach to chest pain is both time consuming and expensive.

It is against this background that the concept of $A \& E$ based chest pain evaluation units emerged - the aim being to provide medically equivalent care at a lower cost for $\mathrm{A} \& \mathrm{E}$ chest pain patients with a probability for ACS that is low, but not sufficiently low to allow discharge. The concept originated in, and has been almost exclusively confined to, the United States. The first chest pain evaluation unit was set up in 1981 and, by $1997,15 \%$ of emergency departments in the US had followed suit. ${ }^{6}$ The aim of this paper is to review the literature on chest pain evaluation units to answer the following questions:

Royal Gwent Hospital, Newport NP9 2UB

Correspondence to: Dr Quin, Senior Registrar in Accident and Emergency Medicine

(gareth.quin@gwent. wales.nhs.uk)

Accepted for publication 8 December 1999
- How are patients managed on chest pain evaluation units?

- Is there evidence for their clinical effectiveness?

- Are they cost effective?

- Is there evidence for patient satisfaction?

\section{Methods}

A literature search was carried out to identify research papers and articles whose principal focus was chest pain evaluation units run by emergency departments for the assessment of chest pain of possible cardiac origin. The following databases were searched-Medline, EMBASE, the Cochrane library and the Database of Abstracts of Reviews for Effectiveness. The following $\mathrm{MeSH}$ terms were used"emergency service, hospital", "myocardial infarction/diagnosis", "myocardial ischaemia/ diagnosis", “angina pectoris/diagnosis", "chest pain/diagnosis", "chest pain/therapy" "cost benefit analysis", and "randomised controlled trials". In addition, the reference lists of retrieved articles were searched for papers not identified in the computerised search. Journals were not hand searched and authors were not contacted for unpublished work. Papers were selected if they described patient management or presented evidence for clinical efficacy, cost effectiveness or patient satisfaction. Where appropriate, papers were critically appraised along standard guidelines. ${ }^{78}$ Conference abstracts were not selected as the brevity of information hinders meaningful critical appraisal.

\section{Results}

PATIENT MANAGEMENT

Eight papers were identified, describing the management process in six chest pain evaluation units. These are summarised in table 1. Despite differences in the detail, the overall approach to patient management is similar in the different centres. All are described as being located in, or adjacent to, the emergency department. All centres include patients with non-traumatic chest pain deemed to be at low risk for AMI. In four centres, the ascription of risk is at the discretion of the treating physician, according to local guidelines. In the other two units, risk is determined according to the Goldman algorithm, a validated tool that subdivides patients with chest pain into groups with differing probabilities of AMI, based on history, examination and ECG findings. ${ }^{15}$ Patients are eligible for these chest pain evaluation units if they have a probability of AMI that is calculated to be less than $7 \%$.

Exclusion criteria are described for five of the centres. Common exclusion criteria are ECG evidence of acute myocardial ischaemia or the presence of complications of cardiac ischaemia (for example, arrhythmia, hypotension, CCF, pre-hospital cardiac arrest). The identification of a non-cardiac diagnosis is stated as an exclusion criterion in four of the 
Table 1 Management protocols in six chest pain evaluation units

\begin{tabular}{|c|c|c|c|c|}
\hline First author & $\begin{array}{l}\text { Duration of } \\
\text { protocol (h) }\end{array}$ & $E C G$ & Biochemical markers & Additional testing \\
\hline Zalenski $^{9}$ & 12 & $0,6,12$ hours & CK-MB at $0,4,8,12$ hours & ETT \\
\hline Gibler $^{10}$ & 9 & $\begin{array}{l}\text { Continuous ST segment } \\
\text { monitor }\end{array}$ & $\mathrm{CK}-\mathrm{MB}$ at $0,3,6,9$ hours & 2-D echo, ETT \\
\hline Hoekstra $^{11}$ & 9 & $\begin{array}{l}\text { Continuous ST segment } \\
\text { monitor }\end{array}$ & CK-MB at $0,3,6,9$ hours & Thallium ETT \\
\hline Doherty $^{12}$ & 9 & $0,3,6,9$ hours & $\mathrm{CK}-\mathrm{MB}$ at $0,3,6,9$ hours & $\begin{array}{l}\text { Cardiology consult, ETT, } \\
\text { Thallium ETT, MUGA } \\
\text { scan }\end{array}$ \\
\hline Mikhail $^{13}$ & 8 & $\begin{array}{l}\text { Continuous ST segment } \\
\text { monitor }\end{array}$ & $\begin{array}{l}\text { Total CK at } 0 \text { hours } \\
+/- \text { CK-MB at } 0,4,8 \text { hours } \\
+/- \text { myoglobin at } 0,4 \text { hours }\end{array}$ & $\begin{array}{l}\text { ETT, Stress echo } \\
\text { Dobutamine echo, } \\
\text { Thallium ETT }\end{array}$ \\
\hline Gomez $^{14}$ & 9 & $\begin{array}{l}\text { Continuous ST segment } \\
\text { monitor }\end{array}$ & $\begin{array}{l}\text { Total CK + CK-MB at } 0,3,6,9 \\
\text { hours }\end{array}$ & ETT, Dobutamine echo \\
\hline
\end{tabular}

ETT, exercise tolerance test; echo, echocardiogram.

five centres. Two units exclude patients with a history of coronary artery disease, while one specifically includes these patients. Inability to perform an exercise test excludes patients in one centre.

Once admitted to the units, patients are subjected to serial clinical, ECG and biochemical assessment at specified intervals. If evidence of AMI or unstable angina emerges the patient is transferred to critical care unit. Patients with normal results at the end of the testing period undergo exercise stress testing, or an equivalent in those physically unfit for the treadmill. If these tests are positive the patient is admitted for further evaluation. If negative, the patient is discharged home. Follow up is arranged with a cardiologist or family physician.

CLINICAL EFFICACY

An effective chest pain evaluation unit should have a diagnostic protocol that performs as well as standard management. The gold standard for evaluating a new diagnostic test (chest pain evaluation unit) entails its independent, blind comparison with a reference standard of diagnosis (standard inpatient management), the reference being applied irrespective of the new test result. ${ }^{16}$ Five published studies have assessed the diagnostic utility of their chest pain evaluation unit's protocol, but only one meets the above criterion. Zalenski et al ${ }^{9}$ studied 317 patients all of whom were initially admitted to a chest pain evaluation unit. At the end of the testing protocol, all patients were admitted to hospital for the establishment of reference diagnoses according to the standard inpatient examination. Final reference diagnoses were assigned by a physician blinded to the results of the chest pain evaluation unit outcomes. The sensitivity and specificity of the protocol for acute coronary insufficiency were $90 \%(95 \%$ CI $73.4 \%$ to $97.9 \%$ ) and $50.5 \%$ (95\% CI $44.6 \%$ to $56.4 \%$ ) respectively. Negative and positive predictive values were $98 \%$ (95\% CI $94.2 \%$ to $99.6 \%$ ) and $16 \%$ respectively. The authors assume a sensitivity of $100 \%$ for the inpatient protocol.

Four other papers used the incidence of adverse outcomes over a period of follow up as a measure of the diagnostic accuracy of their protocol. Table 2 summarises the results.

The proportion of patients discharged home after the protocol, duration of stay, the frequency with which ischaemic heart disease
Table 2 Outcomes of patients discharged from four chest pain evaluation units

\begin{tabular}{|c|c|c|c|}
\hline First author & $\begin{array}{l}\text { Number of } \\
\text { patients * }\end{array}$ & $\begin{array}{l}\text { Period of } \\
\text { follow up }\end{array}$ & Adverse outcomes \\
\hline Doherty $^{12}$ & 176 & 9 months & Nil \\
\hline Mikhail $^{13}$ & 410 & 5 months & 1 AMI at 6 days \\
\hline Gibler $^{10}$ & 829 & 1 month & $\begin{array}{l}1 \text { AMI at } 3 \text { days } \\
4 \text { non-cardiac } \\
\text { deaths at } 1 \text { month }\end{array}$ \\
\hline Gomez $z^{14}$ & 46 & 30 days & Nil \\
\hline
\end{tabular}

AMI, acute myocardial infarction. *Number of patients discharged after negative chest pain unit evaluation.

is diagnosed in all chest pain unit patients and in those admitted with positive results all relate to the effectiveness of the unit. Table 3 summarises the available evidence on these issues.

COST COMPARISONS

Four papers report comparative studies with cost as a primary outcome. Roberts et $a l^{18}$ randomly allocated 166 chest pain evaluation unit eligible patients to either chest pain unit (intervention) or standard inpatient treatment (control). The mean total cost per chest pain unit patient was $\$ 1528$ compared with $\$ 2095$ for controls $(p<0.01)$. Mean costs for patients admitted after chest pain unit evaluation were $\$ 2410$, higher than the cost for patients discharged after chest pain unit evaluation $(\$ 803, \mathrm{p}<0.001)$ and for controls $(\$ 2095$, $\mathrm{p}<0.13)$. This study was well designed with robust randomisation, clearly stated sample size calculations, intention to treat analysis and rigorous cost analysis. Blinding was not possible as patients were managed in different areas.

In a second randomised controlled trial, Gomez et $a l^{14}$ reported mean hospital charges of $\$ 1297$ in the chest pain unit group versus $\$ 5719$ in the routine care (control) group $(p<0.0001)$. Figures are not presented for the cost differences between those admitted from the chest pain unit and those discharged.

Mikhail et $a l^{13}$ report a comparative study using retrospective controls. The mean total cost per case for patients discharged from the chest pain unit was $\$ 894$. The corresponding figure for controls was $\$ 2364$.

In another non-randomised trial, Hoekstra et $a l^{11}$ report a cost analysis for chest pain units in two centres. Patients admitted to the hospitals when the chest pain units were full were used as controls. In both centres, mean charges were significantly less for chest pain unit patients 
Table 3 Outcomes of patients admitted to chest pain evaluation units

\begin{tabular}{|c|c|c|c|c|}
\hline Author & Discharged (\%) & Duration (control) & $\begin{array}{l}\% \text { Admitted with } \\
A C S^{\star}\end{array}$ & $\begin{array}{l}\text { \% CPEU patients with } \\
\text { ACSt }\end{array}$ \\
\hline $\begin{array}{l}\text { Gomez }^{14} \\
\text { (RCT) }\end{array}$ & 92 & $\begin{array}{l}15.4 \text { hours } \\
\text { ( } 54.6 \text { hours) }\end{array}$ & 25 & 2 \\
\hline Doherty $^{12}$ & 78 & $\begin{array}{l}17.4 \text { hours } \\
\text { ( } 52.8 \text { hours) }\end{array}$ & 10 & 2 \\
\hline Toner $^{17}$ & 72 & 6.5 hours & $\mathrm{N} / \mathrm{S}$ & $\mathrm{N} / \mathrm{S}$ \\
\hline Gibler $^{10}$ & 82.1 & $\mathrm{~N} / \mathrm{S}$ & 28.1 & 4.25 \\
\hline Mikhail $^{13}$ & 86 & $\mathrm{~N} / \mathrm{S}$ & 66 & 9 \\
\hline
\end{tabular}

^Percentage of patients admitted from the chest pain evaluation unit with an eventual diagnosis of an acute coronary syndrome. $\nmid$ Percentage of all patients admitted to the chest pain evaluation unit with a final diagnosis of an acute coronary syndrome. N/S, not stated; RCT, randomised controlled trial.

than controls (Centre 1: $\$ 2797$ v $\$ 3957$ $(\mathrm{p}=0.009) ; \quad$ Centre 2: $\$ 1931$ v $\$ 3961$ $(\mathrm{p}=0.002))$. This paper also reports higher mean charges in patients admitted following chest pain unit evaluation than in controls, although these differences were not statistically significant.

PATIENT SATISFACTION

Rydman $a t a l^{19}$ report a randomised controlled trial comparing patient satisfaction between chest pain observation unit patients and controls admitted for routine care, using patient interviews to score a number of satisfaction markers from 1 (most dissatisfied) to 4 (most satisfied). The chest pain unit scored higher than inpatient management on all seven satisfaction indices, with the attainment of a statistically significant difference in four of these scores.

\section{Discussion}

The management strategy used in chest pain evaluation units represents a condensed form of traditional inpatient management. Protocols differ in some of their components, although no study has compared one with another. Recent evidence on the performance of Troponin $\mathrm{T}$ and Troponin I in patients with chest pain and normal ECGs offers the prospect of even shorter testing periods. In a well designed validation study, Hamm and colleagues ${ }^{5}$ report that Troponin $\mathrm{T}$ and Troponin I tests were positive in $94 \%$ and $100 \%$ (respectively) of patients with AMI within six hours of pain onset, although this study was not carried out in the context of a chest pain unit.

All units perform some form of provocative testing before discharge. This practice recognises the safety of early exercise testing in chest pain patients with a low risk of $\mathrm{ACS}^{20}$ and the dangers of omitting such testing-Gaspoz et $\mathrm{al}^{22}$ reported a $1.2 \%$ missed $\mathrm{MI}$ rate in patients discharged from a cardiology run chest pain observation unit, only $19 \%$ of whom had had an exercise test before discharge.

It is clear that the success of these units stands or falls on rapid and extended access to cardiac enzyme assays and stress testing facilities. Most of the reporting US centres can access blood assays 24 hours a day and exercise testing seven days a week. Excluding patients unable to perform exercise tests may simplify the logistics, by obviating the need for rapid access to more sophisticated provocation tests, but would probably limit the usefulness of the unit.

Despite the considerable investment required, chest pain units may have a modest impact on chest pain management in a given department. In a feasibility study, Zalenski et $a l^{1}$ found that only $28 \%$ of patients deemed to be at low risk for MI were eligible for the chest pain unit. Characteristics of the study population, protocols used and chest pain unit exclusion criteria all impact on this proportion.

The available evidence suggests that chest pain evaluation units deliver what they promise, providing equivalent clinical outcomes to inpatient management, in a shorter time and for less money. Follow up of discharged patients has demonstrated the safety of the protocols, although given the sensitivity of $90 \%$ reported by Zalenski et $a l,{ }^{9}$ and with a disease prevalence of $10 \%$, approximately 1 in 100 tested patients would be wrongly classified as being disease free. The specificities of the protocols are moderate and most patients admitted having had a positive result in the chest pain unit prove ultimately not to have an acute coronary syndrome (table 3 ). This underscores the limitations of current diagnostic tests.

Two well designed studies have demonstrated the cost-benefits of chest pain evaluation units. The important observation is that patients managed on the unit who are subsequently admitted cost more than those managed in the routine way. Savings can only be made if a majority of those managed on the unit are discharged. Most units achieve this (table 3). It is probable that some patients will be admitted to the unit who would otherwise have been discharged after initial A\&E evaluation. This is essential to decrease missed MI rates but will impact on overall cost effectiveness.

There is a potential in chest pain evaluation units for overlooking other causes of chest pain, given the overwhelming focus on excluding cardiac disease. Many of these alternative diagnoses are not readily apparent and some may have serious consequences. In addition, chest pain evaluation units run the risk of downplaying the importance of symptoms other than chest pain in the presentation of myocardial ischaemia. These potential pitfalls have received little attention in the literature, though it seems likely that focused education would lessen the risk.

It is estimated that, since 1991, over 500 chest pain evaluation units have been established in emergency departments across the United States. ${ }^{23}$ There are no published reports of such A\&E based units from any other country. Retrospective denial of payment for patients admitted with non-cardiac chest pain is not an uncommon occurrence in the US, ${ }^{3}$ and it is clear from the literature that financial pressures have had a significant role in the development of chest pain evaluation units. Of the three randomised controlled trials identified, two centre on cost. The clinical benefits are largely reported in observational studies. Whatever their origin, the role of chest pain 
units continues to develop in the US, with the recent publication of the results of a randomised trial reporting the safe, clinically and cost effective use of a chest pain observation unit for the treatment of patients with unstable angina deemed to be at intermediate risk for cardiac events. $^{24}$

\section{Conclusion}

Do chest pain evaluation units have a role in UK A\&E practice? Experience in the US has demonstrated that such units manage patients at low risk for MI as effectively as inpatient admission, and at less cost. They seem like a good idea. However, all available evidence emanates from the US and may not be generalisable to the UK. Their institution in the UK would require staffing levels and access to diagnostic facilities currently beyond most centres. Feasibility and cost-benefit studies would need to inform any change in local practice. Close collaboration with the cardiology service would be essential.

In the current absence of a clinical or financial imperative to establish chest pain evaluation units, their appearance in UK $A \& E$ practice may well reflect local opinion on whether such activity constitutes seizing the initiative or shouldering the burden.

Funding: none.

Conflicts of interest: none

1 Zalenski RJ, Rydman RJ, McCarren M, et al. Feasibility of a rapid diagnostic protocol for an emergency department chest pain unit. Ann Emerg Med 1997;29:99-108.

2 Graff LG, Dallara J, Ross MA, et al. Impact on the care of the emergency department chest pain patient from the chest pain evaluation registry. Am 7 Cardiol 1997;80:563-8.

3 Gibler WB. Chest pain evaluation in the ED: beyond triage. Am f Emerg Med 1994;12:121-2.

4 Fesmire FM, Percy RF, BardonerJB, et al. Usefulness of automated serial 12-lead ECG monitoring during the initial emergency department evaluation of patients with chest pain. Ann Emerg Med 1998;31:3-11

5 Hamm CW, Goldman BU, Heechsen C, et al. Emergency room triage of patients with acute chest pain by means of rapid testing for cardiac troponin T or troponin I. N Engl F Med 1997;337:1648-53.
6 Hoekstra JW, Gibler WB. Chest pain evaluation units-an idea whose time has come. $\mathcal{F A M A}$ 1997;278:1701-2.

7 Greenhalgh T. How to read a paper. London: BMJ Publications, 1997.

8 Crombie IK. The pocket guide to critical appraisal. London: BMJ Publications, 1996.

9 Zalenski RJ, McCarren M, Roberts R, et al. An evaluation of a chest pain diagnostic protocol to exclude acute cardiac ischaemia in the emergency department. Arch Intern Med 1997;157:1085-91.

10 Gibler WB, Runyon JP, Levy RC, et al. A rapid diagnostic and treatment center for patients with chest pain in the emergency department. Ann Emerg Med 1995;25:1-7.

11 Hoekstra JW, Gibler WB, Levy RC, et al. Emergencydepartment diagnosis of acute myocardial infarction and ischemia: a cost analysis of two diagnostic protocols. Acad Emerg Med 1994;1:103-10.

12 Doherty RJ, Barish RA, Groleau G. The Chest Pain Evaluation Center at the University of Maryland Medical Center. Md Med f 1994;42:1047-52.

13 Mikhail MG, Smith FA, Gray M, et al. Cost-effectiveness of mandatory stress testing in chest pain centre clinics. Ann Emerg Med 1997;29:88-97.

14 Gomez MA, Anderson JL, Karagounis LA, et al. An emergency department-based protocol for rapidly ruling out myocardial eschaemia reduces hospital time and expense: results of a randomized study (ROMIO). $7 \mathrm{Am}$ expense: results of a rando

15 Goldman L, Cook EF, Brand DA, et al. A computer proto$\mathrm{col}$ to predict myocardial infarction in emergency department patients with chest pain. N Engl F Med 1988;318:797803.

16 Sackett DL, Richardson WS, Rosenberg W, et al. Evidencebased medicine. How to Practice and teach EBM. Newport: Churchill Livingstone, 1997:97-9.

17 Toner ES. Saint Joseph Medical Center emergency department chest pain center. Md Med f 1997; suppl:46-7.

18 Roberts RR, Zalenski RJ, Mensah EK, et al. Costs of an emergency department-based accelerated diagnostic protocol vs hospitalisation in patients with chest pain. $\mathscr{f} A M A$ 1997;278:167076.

19 Rydman RJ, Zalenski RJ, Roberts RR. Patient satisfaction with an emergency department chest pain observation unit. Ann Emerg Med 1997;29:109-15.

20 Gaspoz J-M, Lee TH, Weinstein MC, et al. Costeffectiveness of a new short-stay unit to "rule out" myocardial infarction in low risk patients. F Am Coll Cardiol 1994; 24:1249-59.

21 Kirk JD, Turnipseed S, Lewis RL, et al. Evaluation of chest pain in low-risk patients presenting to the emergency department: the role of immediate exercise testing. Ann Emerg Med 1998;32:1-7.

22 Kerns JR, Shaub TF, Fontanarosa PB. Emergency cardiac stress testing in the evaluation of emergency department stress testing in the evaluation of emergency department
patients with atypical chest pain. Ann Emerg Med 1993;22: patient

23 Zalenski RJ, Rydman RJ, Ting S, et al. A national survey of emergency department chest pain centers in the United States. Am F Cardiol 1998;81:1305-9.

24 Farkouh ME, Smars PA, Reeder GS, et al. A clinical trial of a chest-pain observation unit for patients with unstable angina. $N$ Engl f Med 1998;339:1882-8. 